\title{
BIRTH-WEIGHT DIFFERENCES OF ROMA AND NON-ROMA NEONATES - PUBLIC HEALTH IMPLICATIONS FROM A POPULATION-BASED STUDY IN HUNGARY
}

\author{
Péter Balázs ${ }^{1}$, Ildikó Rákóczi², Andrea Grenczer ${ }^{3}$, Kristie L. Foley ${ }^{4}$ \\ ${ }^{1}$ Institute of Public Health, Semmelweis University, Budapest, Hungary \\ ${ }^{2}$ Department of Family Care, University of Debrecen, Nyíregyháza, Hungary \\ ${ }^{3}$ Department of Family Care Methodology, Semmelweis University, Budapest, Hungary \\ ${ }^{4}$ Medical Humanities Program, Davidson College, Davidson, NC, USA
}

\section{SUMMARY}

Objective: This study analyses the role of ethnicity-based birth weight differences at term (37-42 weeks) between neonates of Roma and nonRoma populations in Hungary, controlling for socio-demographic and biological characteristics of the mothers.

Methods: A cross-sectional survey among 9,040 mothers coupled with biometric data of the neonates was conducted in 2010 . Inclusion criteria were: at term (37-42 weeks gestation) non-pathological pregnancies, and self-reported ethnicity. Birth weight was based on mothers' ethnicity, age, body mass index, education, marital and employment status, poverty level, household amenities, dietary and smoking habits using multiple linear regression.

Results: The mean difference between Roma and non-Roma neonates measured without controlling for possible confounding factors was -288.7 grams $(p<0.001,95 \% \mathrm{Cl}=-313.4-263.9)$. In the linear regression model Roma neonates weighed on average 69.67 grams less than nonRoma neonates $(\mathrm{p}<0.001,95 \% \mathrm{Cl}=30.51-108.83)$. The mother's underweight $\mathrm{BMI}$, low education and smoking during pregnancy $(\mathrm{p}<0.001)$, age under 18 years, no amenities of housing and insufficient consumption of fruits and dairy products also significantly influenced $(p<0.05)$ the neonates' birth weight.

Conclusion: Roma ethnicity was independently correlated with lower birth-weight among at term neonates, controlling for known risk factors. Roma ethnicity may serve as a proxy for other unmeasured social or biological factors and should be considered an important covariate for measurement among neonates.

Key words: birth weight, at term neonates, Roma ethnicity, biological factors, socioeconomic factors

Address for correspondence: P. Balázs, Institute of Public Health, Semmelweis University, Nagyvárad tér 4, H-1089 Budapest, Hungary. E-mail: balazs-peter@windowslive.com

\section{INTRODUCTION}

Biomedical studies have shown that birth weight varies considerably across ethnic groups, which was demonstrated as early as in 1970 by a worldwide comparative treatise (1). A recent comprehensive literature review (2) stressed the significance of sociobiological variables on pregnancy outcomes. According to the study using data from nine countries in Europe, Asia, Africa, and the Caribbean the birth weight varied widely (mean values 2,730-3,570 g) of singleton, full-term (at least 37 weeks) live born babies. The authors emphasized that geographical variation in neonatal phenotype are likely to be multiple. Genetic factors are likely to influence the size and shape by foetal growth hormones. Factors of the environment act on the maternal-foetal supply, which includes the mother's dietary intake, metabolism, endocrine status, body composition, hemodynamic and vascular function, and the microstructure and function of the placenta.

In Hungary, the Carpathian Roma arrived by first migration wave in the 1400s, and the Vlax Roma in the 19th century. Vlax Roma settled in the eastern regions of the country and preserved their own language and socio-cultural traditions. Following the significant political and economic changes in the late 1980s, a new wave of Roma migration toward Western Europe instigated new research activities about the origin and demographic phenomena of this population. Genetic research based on chromosome variations of 14 well-defined Roma populations was consistent with a single ethnic population in the Indian subcontinent (3). A recent genetic study of Vlax Roma in Hungary also supported the migration route from India through the Balkans to the Carpathian Basin (4).

The European Union Framework for National Roma Integration Strategies up to 2020 also contains basic demographic data (5). Hungary has the fourth largest estimated proportion of Roma population (7.05\%) after Bulgaria (10.33\%), the Slovak Republic (9.17\%) and Romania (8.32\%). Western European countries have a lower number of Roma populations although actual numbers of Roma are comparable. For example, Roma in Spain represent approximately $1.57 \%$ of the total population, but are roughly 725,000 persons. The average estimated numbers are nearly identical to number of Roma in Hungary $(700,000)$ and Bulgaria $(750,000)$. 
Two studies concerning unfavourable birth outcomes of the Central European Roma population $(6,7)$ found a crude difference of 373 grams and 289 grams between Roma and non-Roma neonates, respectively. Like these studies, further articles published about Roma living in Europe and especially in Central-Eastern Europe also emphasized these populations' poor health resulting from low socioeconomic status (SES), severe social exclusion, unfavourable behavioural patterns, and the environment, all of which could influence birth outcome (8-15).

The aim of this study was to obtain obstetrical and socioeconomic data of Roma and non-Roma populations in Hungary's two north-eastern counties to support or reject the hypothesis whether Roma ethnicity itself was a factor contributing to lower birth weight if compared with the non-Roma Hungarian population. Further, we wanted to estimate the absolute magnitude of the birth-weight difference, should such a difference exist. We focused our research on full-term, singleton births and removed the most frequent maternal and neonatal pathological cases that could skew the results of the research.

\section{MATERIALS AND METHODS}

Inhabitant mothers in counties Borsod-Abauj-Zemplen (population 692,771) and Szabolcs-Szatmar-Bereg (population $560,429)$ with live births (6,927 and 5,806 respectively) in 2009 were visited in their homes using the register of the local Maternity and Child Health Service (MCHS). Interviews were conducted between 1 January and 30 June 2010. Respondents and nonrespondents were equally represented in the sub-regions of both counties; $29 \%$ ( $n=3,693$ ) did not participate either because they were not home at the time the interviewer tried to reach them or indicated that the time was inconvenient to be interviewed and requested the interviewer to return. All contacts were made twice. Ultimately, $n=9,040$ (71.0\%) consented to participate in the study. Babies with multiple births (73 twins and 1 triplet), born before the 37 th and after the 42 th week $(n=733+96$ missing values) and congenital abnormalities ( $\mathrm{n}=389+59$ missing values) were excluded. Mothers with gestational or pre-gestational diabetes mellitus ( $n=418+29$ missing values), high blood pressure ( $n=$ $808+18$ missing values) and proteinuria $(\mathrm{n}=711+18$ missing values) were also excluded. After exclusions $(n=6,425) 1,643$ identified themselves as Roma and 3,989 as non-Roma. The final sample included 5,632 mothers with their babies.

\section{Measurement}

With few exceptions, all deliveries in Hungary are performed in hospitals; therefore, birth weight data were based on hospital records at the time of birth. Biomedical data of mothers measured by the maternal and child health service before pregnancy were used to calculate body mass index $\left(\mathrm{BMI}=\mathrm{kg} / \mathrm{m}^{2}\right.$ i.e. body mass in kilogram divided by height in meters squared) and converted to a categorical variable (BMI underweight $\leq 18.49$, normal weight $=18.5-24.9$, overweight $=25-29.9$, obese $=30$ or greater .

The questionnaire included standardized measures of demographic, socioeconomic, and lifestyle characteristics. Ethnicity was self-reported. Demographic data included the mothers' age and family status. SES was measured by educational level, in- come/capita in the family, housing conditions, and the mothers' employment status before birth.

While there is no legal poverty level in Hungary, the statistical poverty level is published annually by the Central Statistical Office and can be used as a proxy for poverty status. Based on the EU standard, $60 \%$ of the median income equals the income poverty level (16). Deep poverty was defined as < $50 \%$ of this level. No amenities in housing conditions were ascertained as no connection to the water supply mains, to the sewage system nor operational individual heating. Partial amenities concerned to be connected to the water supply mains without connection to the sewage system and without operational individual heating. In case of full amenities the households were connected to the water supply mains, to the sewage system and had operational central heating.

Lifestyle questions included dietary and tobacco smoking habits. Poor nutritional characteristics concerned the consumption of fresh fruits, vegetables, dairy and meet products less than every other day opposed to the more frequent category. Non-smoking during pregnancy included those who were prior non-smokers as well as those who quit when they learned they were pregnant. Smoking during pregnancy was based on self-admitted number of cigarettes from 1 to 30 or more a day.

\section{Analysis}

For calculating bivariate associations of Roma versus nonRoma ethnicity related to all variables we computed odds ratios (ORs) at 95\% confidence interval (CI) and at significance level of $p<0.05$. While assessing normality of birth weight data the graphical interpretation showed normal distribution. Bivariate statistics of all variables were conducted using t-tests to compare the means of birth weights in the study. In the second stage, we applied a linear regression model for birth weight differences. Results are reported in mean differences with standard error and $95 \%$ CI at significance level of $\mathrm{p}<0.05$. IBM-SPSS (version 20.0) was used for all statistical analyses.

\section{RESULTS}

Total and ethnicity-related birth weight data of the neonates after non-pathological pregnancies are presented in Table 1. Between the Roma and non-Roma sample the mean weight difference is $289 \mathrm{~g}$ while the difference of median values is $300 \mathrm{~g}$.

Table 1. Birth weight data of at term (37-42 weeks) Roma and non-Roma neonates in two north-eastern counties in Hungary in 2009

\begin{tabular}{|c|c|c|c|}
\hline \multicolumn{2}{|l|}{ Total } & Roma & Non-Roma \\
\hline $\mathrm{N}$ of respondents & 5,632 & 1,643 & 3,989 \\
\hline Mean & 3,281 & 3,076 & 3,365 \\
\hline Median & 3,270 & 3,050 & 3,350 \\
\hline Mode & 3,000 & 3,000 & 3,300 \\
\hline Std. deviation & 461.588 & 422.011 & 450.775 \\
\hline Minimum & 1,460 & 1,790 & 1,460 \\
\hline Maximum & 5,400 & 4,500 & 5,400 \\
\hline
\end{tabular}


Among Roma the maximum value is $900 \mathrm{~g}$ less than that of the non-Roma sample.

Table 2 demonstrates the mean differences in birth weight by dichotomized ethnicity, maternal biometric, socio-demographic and lifestyle variables. Differences were significant in all analysed variables. The greatest birth weight difference $(-327.3 \mathrm{~g})$ was indicated by tobacco smoking during pregnancy followed by basic or less education (-296.4). Roma ethnicity meant -288.7 $\mathrm{g}$ difference in birth weight followed closely by the impact of no amenities of housing conditions $(-287.4 \mathrm{~g})$.

Table 2. Bivariate model of mean birth weight differences of at term (37-42 weeks) neonates related to the mother's ethnicity, biometric and socioeconomic characteristics in two north-eastern counties in Hungary in 2009

\begin{tabular}{|c|c|c|c|c|}
\hline Variables (n/n) & Mean difference & Std. error & $95 \% \mathrm{Cl}$ & $\mathrm{p}$ \\
\hline Roma vs. non-Roma $(1,643 / 3,989)$ & -288.7 & 12.6 & $-313.4-263.9$ & $<0.001$ \\
\hline age $<18$ years vs. others $(212 / 5,392)$ & -267.1 & 32.1 & $-330.1-204.2$ & $<0.001$ \\
\hline BMl underweight vs. others $(794 / 4,577)$ & -254.2 & 16.3 & $-286.3-222.2$ & $<0.001$ \\
\hline Education basic vs. more $(2,056 / 3,557)$ & -296.4 & 12.2 & $-320.3-272.5$ & $<0.001$ \\
\hline Unemployed ${ }^{1}$ vs. employed $(3,210 / 2,401)$ & -195.3 & 12.2 & $-219.2-171.4$ & $<0.001$ \\
\hline Non-married vs. married $(2,600 / 3,015)$ & -171.4 & 12.2 & $-195.2-147.6$ & $<0.001$ \\
\hline Deep poverty vs. others $(2,436 / 2,980)$ & -239.5 & 12.2 & $-263.4-215.6$ & $<0.001$ \\
\hline No amenities vs. partial/full $(1,079 / 4,224)$ & -287.4 & 14.5 & $-315.9-258.8$ & $<0.001$ \\
\hline Fruits less than every other day vs. more often $(1,112 / 4,485)$ & -214.4 & 15.2 & $-184.6-244.1$ & $<0.001$ \\
\hline Vegetables less than every other day vs. more often $(1,347 / 4,248)$ & -168.6 & 14.2 & $-140.7-196.5$ & $<0.001$ \\
\hline Dairy less than every other day vs. more often $(947 / 4,646)$ & -176.6 & 16.3 & $-144.7-208.5$ & $<0.001$ \\
\hline Meat less than every other day vs. more often $(985 / 4,586)$ & -112.0 & 16.1 & $-80.4-143.6$ & $<0.001$ \\
\hline Smoking during pregnancy $Y / N(1,363 / 3,880)$ & -327.3 & 13.5 & $-353.8-300.8$ & $<0.001$ \\
\hline
\end{tabular}

T-test was used for mean differences

${ }^{1}$ Unemployed category contains also students and mothers on social support

Table 3. Bivariate association of Roma versus non-Roma ethnicity with maternal biometric, socio-demographic and lifestyle variables

\begin{tabular}{|c|c|c|c|}
\hline Variables & OR & $95 \% \mathrm{Cl}$ & $p$ \\
\hline $\begin{array}{l}\text { Roma vs. non-Roma }(1,630 / 3,974) \\
\text { age }<18 \text { years vs. others }(212 / 5,392)\end{array}$ & 10.26 & $7.33-14.38$ & $<0.001$ \\
\hline $\begin{array}{l}\text { Roma vs. non-Roma }(1,630 / 3,974) \\
\text { BMl underweight vs. others }(794 / 4,577)\end{array}$ & 2.42 & $2.07-2.82$ & $<0.001$ \\
\hline $\begin{array}{l}\text { Roma vs. non-Roma }(1,635 / 3,978) \\
\text { Education basic vs. more }(2,056 / 3,557)\end{array}$ & 38.20 & $32.22-45.30$ & $<0.001$ \\
\hline $\begin{array}{l}\text { Roma vs. non-Roma }(1,635 / 3,976) \\
\text { Unemployed }{ }^{1} \text { vs. employed }(3,210 / 2,401)\end{array}$ & 28.46 & $22.45-36.09$ & $<0.001$ \\
\hline $\begin{array}{l}\text { Roma vs. non-Roma }(1,637 / 3,978) \\
\text { Non-married vs. married }(2,600 / 3,015)\end{array}$ & 5.63 & $4.95-6.41$ & $<0.001$ \\
\hline $\begin{array}{l}\text { Roma vs. non-Roma }(1,602 / 3,814) \\
\text { Deep poverty vs. others }(2,436 / 2,980)\end{array}$ & 18.72 & $15.88-22.05$ & $<0.001$ \\
\hline $\begin{array}{l}\text { Roma vs. non-Roma }(1,538 / 3,765) \\
\text { No amenities vs. partial/full }(1,079 / 4,224)\end{array}$ & 17.88 & $15.16-21.09$ & $<0.001$ \\
\hline $\begin{array}{l}\text { Roma vs. non-Roma }(1,633 / 3,964) \\
\text { Fruits less than every other day vs. more often }(1,112 / 4,485)\end{array}$ & 5.06 & $4.41-5.82$ & $<0.001$ \\
\hline $\begin{array}{l}\text { Roma vs. non-Roma }(1,633 / 3,962) \\
\text { Vegetables less than every other day vs. more often }(1,347 / 4,248)\end{array}$ & 3.84 & $3.38-4.37$ & $<0.001$ \\
\hline $\begin{array}{l}\text { Roma vs. non-Roma }(1,632 / 3,961) \\
\text { Dairy less than every other day vs. more often }(947 / 4,646)\end{array}$ & 3.61 & $3.12-4.17$ & $<0.001$ \\
\hline $\begin{array}{l}\text { Roma vs. non-Roma }(1,621 / 3,950) \\
\text { Meat less than every other day vs. more often }(985 / 4,586)\end{array}$ & 2.26 & $1.96-2.60$ & $<0.001$ \\
\hline $\begin{array}{l}\text { Roma vs. non-Roma }(1,599 / 3,644) \\
\text { Smoking during pregnancy } \mathrm{Y} / \mathrm{N}(1,363 / 3,880)\end{array}$ & 4.93 & $4.32-5.63$ & $<0.001$ \\
\hline
\end{tabular}

${ }^{1}$ Unemployed category contains also students and mothers on social support 
Table 4. Multiple linear regression model of at term (37-42 weeks) neonates' birth weight related to ethnicity, biometric and socioeconomic factors $(n=4452)$ with all variables entered simultaneously

\begin{tabular}{|l|c|c|c|c|}
\hline Variables & Weight difference & Std. error & $95 \%$ CI & p \\
\hline Roma vs. non-Roma & 69.67 & 19.97 & $30.51-108.83$ & $<0.001$ \\
\hline Age $<18$ vs. others & 77.35 & 33.33 & $12.01-142.68$ & 0.020 \\
\hline BMl underweight vs. others & 167.59 & 17.95 & $132.40-202.76$ & $<0.001$ \\
\hline Education basic vs. more & 94.29 & 20.70 & $53.70-134.87$ & $<0.001$ \\
\hline Unemployed vs. employed & -12.29 & 16.46 & $-44.56-19.98$ & 0.455 \\
\hline Non-married vs. married & 14.32 & 14.15 & $-13.43-42.07$ & 0.312 \\
\hline Deep poverty vs. others & 4.74 & 17.54 & $-29.64-39.12$ & 0.787 \\
\hline No amenities vs. partial+full & 40.62 & 19.77 & $1.86-79.38$ & 0.040 \\
\hline Fruits less than every other day vs. more often & 51.55 & 20.16 & $12.02-91.82$ & 0.011 \\
\hline Vegetables less than every other day vs. more often daily v. less & -2.60 & 18.51 & $-38.90-33.69$ & 0.888 \\
\hline Dairy less than every other day vs. more often & 47.73 & 18.46 & $11.53-83.93$ & 0,010 \\
\hline Meat less than every other day vs. more often & 4.74 & 17.54 & $-29.64-39.12$ & 0.787 \\
\hline Smoking during pregnancy & 196.22 & 16.28 & $164.30-228.14$ & $<0.001$ \\
\hline
\end{tabular}

The strongest bivariate association in terms of ORs with Roma versus non-Roma ethnicity (Table 3) showed the level of low education (OR 38.20, 95\% CI 32.22-45.30) followed by unemployment (OR 28.46, 95\% CI 22.45-36.09), deep poverty (OR 18.72, 95\% CI 15.88-22.05), lack of amenities (OR 17.88, $95 \%$ CI 15.16-21.09), and young age $<18$ years (OR 10.26, 95\% CI 7.33-14.38).

In a linear regression model (Table 4 ) with $\mathrm{R}^{2}$-value of $16.8 \%$, employment and marital status, poverty level, further dietary habits except consuming fruits and dairy products had no significant impact on the birth weight difference. The greatest significant ( $p<0.001$ ) difference was due to the mother's smoking during pregnancy (196.22 g) and underweight BMI (167.59 g). Roma ethnicity remained significant after controlling for all covariates ( $<<0.001)$; Roma neonates weighted on average 70 grams less, than non-Roma neonates in the multivariate model.

\section{DISCUSSION}

Two the Czech Republic based recent studies available about the birth outcomes of Central European Roma population $(6,7)$ demonstrated a crude negative difference of $373 \mathrm{~g}(\mathrm{n}=1.388$ Roma and $\mathrm{n}=8938$ non-Roma) and $289 \mathrm{~g}$ (n=76 Roma and 151 nonRoma) contrasted to the non-Roma neonates. However, when a great population-based study (6) demonstrated a crude difference of $373 \mathrm{~g}$ between Roma and non-Roma, the birth weight difference dropped considerably (133 g) once adjusted for demographic, socioeconomic and behavioural factors.

In Hungary, the last nationwide study published in 1991 about Roma babies born in 1973-1983 ( $n=10.108)$ used a retrospective sampling technique of obstetrical records of mothers speaking a specific Roma dialect as their first language (17). While comparing the national average of full term birth weight $(3,133 \mathrm{~g})$ with the average weight of Roma neonates (2,756 g) the difference was 377 grams. This study indicated that there might be a genetic element in the lower birth weight, but the disadvantage might stem largely from a low socioeconomic status of the Roma population, which was not measured.

The recent studies $(18,19)$ about birth outcomes of the European populations do not offer disaggregated Roma data for comparison. For example, the first study about maternal education and adverse birth outcomes among immigrant women to the US from Southern and Eastern Europe after the decline of communist systems did not identify Roma ethnicity while analysing immigrants out of Russia, Ukraine, Poland, and the former Yugoslav Republics (18). The western European study about Spain, with a considerable Roma population, and East Asia, Morocco, and South America did not include Roma ethnicity as a covariate (19). In this regard, our study makes a unique contribution to the literature on birth weight differences between Roma and non-Roma neonates.

Our study also reinforces earlier research, demonstrating that socioeconomic conditions, poor nutrition, and tobacco use all contribute to lower birth weight among neonates.

It is important to note that in our final sample $(n=5,632)$ among prior smokers only $11.6 \%$ of Roma women quit throughout pregnancy, as opposed to $53.3 \%$ of non-Roma women. There were significant differences in maternal age, BMI-values, education, employment and marital status, poverty level, housing conditions, dietary and smoking habits between the two populations (Table 3). They are modifiable and represent potential points of intervention.

In the multivariable analysis, the role of ethnicity remains an important correlate of birth weight, but the magnitude of ethnicity's impact is considerably reduced when controlling for sociodemographic and lifestyle characteristics. Thus, it does not appear that ethnicity can be considered a fatal genetic factor having significant impact on lower birth weight of the Roma population. Instead, it is more reasonable to hypothesize that ethnicity is a proxy of other unmeasured socioeconomic and/or cultural patterns influencing birth weight among neonates. However, based on our findings, it seems reasonable to use Roma ethnicity to help identify at risk populations and to tailor public health and preventive obstetrical programmes in these communities. 


\section{Conflict of Interests}

None declared

\section{Sponsorship}

This publication was based on the research project supported by the Fogarty International Centre, the National Cancer Institute and the National Institutes on Drug Abuse within the National Institutes of Health (Grant Number 1 R01 TW007927-01).

\section{Statement on the Ethical Conduct of Research}

This research was reviewed by the Human Subjects' Institutional Review Board at Davidson College, and the Ethical Review Board at Semmelweis University.

\section{REFERENCES}

1. Meredith HV. Body weight at birth of viable human infants: a worldwide comparative treatise. Hum Biol. 1970 May;42(2):217-64.

2. Tambyrajia RL, Mongelli M. Sociobiological variables and pregnancy outcome. Int J Gynaecol Obstet. 2000 Jul;70(1):105-12.

3. Gresham D, Morar B, Underhill PA, Passarino G, Lin AA, Wise C, et al. Origins and divergence of the Roma (Gypsies). Am J Hum Genet. 2001 Dec;69(6):1314-31

4. Zalán A, Béres J, Pamjav H. Paternal genetic history of the Vlax Roma. Forensic Sci Int Genet. 2011 Mar;5(2):109-13.

5. European Commission. Communication from the Commission to the European Parliament, the Council, the European Economic and Social Committee and the Committee of the Regions: An EU Framework for National Roma Integration Strategies up to 2020 [Internet]. Brussels: European Commission; 2011 [cited 2012 Aug 10]. Available from: http:// ec.europa.eu/justice/policies/discrimination/docs/com_2011_173_en.pdf.

6. Bobak M, Dejmek J, Solansky I, Sram RJ. Unfavourable birth outcomes of the Roma women in the Czech Republic and the potential explanations: a population-based study. BMC Public Health. 2005 Oct 10;5:106.

7. Rambousková J, Dlouhý P, Křížová E, Procházka B, Hrnčířová D, Anděl M. Health behaviors, nutritional status, and anthropometric parameters of Roma and non-Roma mothers and their infants in the Czech Republic. J Nutr Educ Behav. 2009 Jan-Feb;41(1):58-64.
8. Parekh N, Rose T. Health inequalities of the Roma in Europe: a literature review. Cent Eur J Public Health. 2011 Sep;19(3):139-42.

9. Kolarcik P, Madarasova Geckova A, Orosova O, van Dijk JP, Reijneveld SA. To what extent does socioeconomic status explain differences in health between Roma and non-Roma adolescents in Slovakia? Soc Sci Med. 2009 Apr;68(7):1279-84.

10. Vokó Z, Csépe P, Németh R, Kósa K, Kósa Z, Széles G, et al. Does socioeconomic status fully mediate the effect of ethnicity on the health of Roma people in Hungary? J Epidemiol Community Health. 2009 Jun;63(6):455-60.

11. Kósa K, Lénárt B, Ádány R. Health status of the Roma population in Hungary. Orv Hetil. 2002 Oct 27;143(43):2419-26. (In Hungarian.)

12. Kósa Z, Széles G, Kardos L, Kósa K, Németh R, Országh S, et al. A comparative health survey of the inhabitants of Roma settlements in Hungary. Am J Public Health. 2007 May;97(5):853-9.

13. Spiroski I, Dimitrovska Z, Gjorgjev D, Mikik V, Efremova-Stefanoska V, Naunova-Spiroska D, et al. Nutritional status and growth parameters of school-age Roma children in the Republic of Macedonia. Cent Eur J Public Health. 2011 Jun;19(2):102-7.

14. Foley KL, Balázs P, Grenczer A, Rákóczi I. Factors associated with quit attempts and quitting among Eastern Hungarian women who smoked at the time of pregnancy. Cent Eur J Public Health. 2011 Jun;19(2):63-6.

15. Hujová Z, Alberty R, Ahlers I, Ahlersová E, Paulíková E, Desatníková J, et al. Cardiovascular risk predictors in Central Slovakian Roma children and adolescents: regional differences. Cent Eur J Public Health. 2010 Sep;18(3):139-44.

16. European Working Condition Observatory. Income poverty in the European Union: Eurostat data on EU income poverty [Internet]. Dublin: Eurofound; 2007 [cited 2013 Mar 8]. Available from: http://www.eurofound.europa.eu/ewco/surveyreports/EU0703019D/EU0703019D_3.htm.

17. Joubert K. Size at birth and some sociodemographic factors in gypsies in Hungary. J Biosoc Sci. 1991 Jan;23(1):39-47.

18. Janevic T, Savitz DA, Janevic M. Maternal education and adverse birth outcomes among immigrant women to the United States from Eastern Europe: A test of the healthy migrant hypothesis. Soc Sci Med. 2011 Aug;73(3):429-35.

19. Figueras F, Meler E, Iraola A, Eixarch E, Coll O, Figueras J, et al. Customized birthweight standards for a Spanish population. Eur J Obstet Gynecol Reprod Biol. 2008 Jan;136(1):20-4.

Received September 19, 2012 Accepted in revised form December 1, 2013 